\title{
Non-invasive analytical techniques applied to characterize the components of ancient golden medallions
}

Jose L Perez-Rodriguez ${ }^{1 *}$, María D Robador ${ }^{2}$, María C Jimenez de Haro ${ }^{1}$, Jose M Martinez Blanes ${ }^{1}$, Isabel Garofano ${ }^{1}$, Carlos Odriozola ${ }^{3}$ and Adrian Duran ${ }^{4}$

\begin{abstract}
Background: The first stable material used to create a gilded surface was gold. False gold was also found in the form of copper-zinc powders or silver covered with resin. There are various ways to make gold leaf adhere to a large surface area. The identification of the materials and processes to make the gilding and the use of noninvasive techniques for gilding study is still an open problem. The gilding of the medallions from the Mudejar palace of Sevilla Alcazar was investigated, and their components were characterised using non-invasive (in situ and laboratory) techniques such as X-ray fluorescence, $\mu$-Raman, infrared spectroscopy, X-ray diffraction and scanning electron microscopy coupled with energy dispersive X-rays. Cross-sections of golden support were also performed and studied by SEM-EDX.
\end{abstract}

Results: The leaf adhered to the surface was primarily a gold alloy. However, copper, silver and zinc were also found. A layer of lead chromate with some lead sulphate was between the alloy and the support. This yellow pigment (lead chromate) and the layers of bole and white lead were characterised in cross-sections prepared from samples taken from the medallions in which the golden layer was missing. The support was composed of gypsum. Another golden layer applied in oldest time period was also found.

Conclusion: The non-invasive techniques provided useful information about the characterisation of the components of the golden medallions. However, complete characterisation of the medallions required the use of other techniques such as mass spectrometry and scanning electron microscopy- energy dispersive X-ray. This is the first time that lead chromate has been detected in gildings. The external gilding was applied at the beginning of the $19^{\text {th }}$ century using mordant oil (linseed oil).

Keywords: XRF portable system, XRD, SEM-EDX, Wall painting, Alloy, Gilding

\section{Background}

The Reales Alcazares of Sevilla is a building inscribed in the World Heritage List as the oldest royal palace still in use in Europe. The Reales Alcazares of Seville constituted a monumental area during the emiral, califal, taifaabbadita, almoravide, almohade and castilian-medieval periods $[1,2]$. The Alcazar of Isbiliya (the ancient name of Seville) was constructed at the end of the first millennium as a fortress during the omeya control of Seville.

\footnotetext{
* Correspondence: jlperez@icmse.csic.es

${ }^{1}$ Materials Science Institute of Seville (CSIC-Sevilla University), Avda Americo Vespucio 49, 41092 Seville, Spain

Full list of author information is available at the end of the article
}

The Alcazar expanded during the subsequent centuries due to the city's increasing political influence within the Iberian Peninsula, and new palaces were built. Abd al Rhaman built the Emiral Palace in 914. The Taifa Palaces of Almuvarak were constructed in the $11^{\text {th }}$ and $13^{\text {th }}$ centuries. In the $13^{\text {th }}$ century, the Golden Tower was built and the Yahward Wall was finished. After the Christian conquest, the Atarazanas and the Gothic Palace were constructed, and several improvements were performed in the $14^{\text {th }}$ century. The Justice Room was constructed, and later the Taifa Palace was rebuilt adjacent to the first building, and the actual Mudejar Palace was constructed. During the subsequent centuries and continuing through
(C) Chemistry Central

(C) 2013 Perez-Rodriguez et al.; licensee Chemistry Central Ltd. This is an Open Access article distributed under the terms of the Creative Commons Attribution License (http://creativecommons.org/licenses/by/2.0), which permits unrestricted use, distribution, and reproduction in any medium, provided the original work is properly cited. 
the present day, the Reales Alcazares was continuously enriched, especially with regard to Renaissance pavilions and gardens, which vastly enlarged the architectonic area.

The Reales Alcazares of Seville is considered to be one of the greatest surviving examples of the Mudejar style. This style did not involve the creation of new structural shapes, but a reinterpretation of Western cultural styles with Islamic influences. For instance, to enliven the planar surfaces of the walls, the Mudejar style developed complicated tiling patterns that have never been surpassed in sophistication.

High-valued wall paintings are located in the Mudejar Palace. Golden medallions, representing the coat of arms of the Leon and Castile Kingdoms, decorate several chamber walls. These artefacts are extremely degraded and require conservation; therefore, studying the materials used to manufacture them and discovering the causes of deterioration is necessary. These medallions have probably been restored several times through centuries.

The first and more stable material used to create a gilded surface was gold. A review performed by Sandu et al. [3] took into consideration the gilded surfaces in polychrome art objects (easel and mural paintings, polychrome wooden objects, gilt leather and parchment) and described the materials, gold application techniques and imitations from a technical, analytical and conservation point of view.

There are various ways to make gold leaf adhere to a large surface area, but the use of fine red clays is the most common method $[4,5]$. For the application of gold on small mural surfaces, the mordant gilding technique is generally used; pieces of gold leaf are attached to the desired areas with an adhesive [6-8]. Cennino Cennini [9] notes the ingredients of the mordant that are boiled together: linseed oil, lead white, verdigris and varnish (sandarac or amber). Thompson [5] describes two types of mordant used in medieval gilding: one is oily and mainly used on panels, wood or wall; another is watery and is used mainly on paper in books sometimes, but never on walls.

$\mathrm{X}$-ray fluorescence spectroscopy is the most widely used technique for elemental chemical analysis due to a number of favourable analytical characteristics [10-12]. Recently, the need to perform in situ non-invasive analysis of art objects, that cannot be easily removed from their location, has led to the development of portable X-ray fluorescence (XRF) equipment. XRF is recognised as being an accurate technique for quantitative analysis. The concentration of one element in a sample is identified as a combination of several factors, such as the measured net peak area within a correcting term corresponding to the effects of the matrix composition and the calibration constant [13-15].

$\mathrm{X}$-ray diffraction is considered to be the best experimental technique for characterising the crystalline phase of artworks. This technique, which is usually performed on powders, is a micro-destructive technique because a small amount of the artwork is collected before performing the experiments. Non-destructive X-Ray diffraction (XRD) equipment was developed to study planar samples using techniques such as grazing incidence X-ray diffraction, which provides very precise information about the surface, atomic interface arrangement in the crystalline structure and composition of the depth profiles [16-18]. In addition, a recent study used Goebel crystal facilities to examine non-planar samples [19].

Raman spectroscopy has become a very useful tool for the analysis of artwork because it is non-destructive, rapid, reproducible and sensitive and also because of its relative low cost compared with other techniques [20-26]. Nevertheless, some artwork materials fail to give an identifiable Raman spectrum either because they are poor Raman scatters or because of their fluorescence.

Small plain pieces or fragments of artwork can be easily transported to a laboratory and studied directly by noninvasive XRD, micro-Raman, micro-FTIR, and SEM/EDX without altering the samples [27-31], that are then returned to their original location.

This study details the use of non-invasive techniques for the characterisation of materials used to make the gilding on the medallions found in the Mudejar Palace of Reales Alcazares. The main objectives of this paper were to elucidate and reconstruct the processes employed to make the gilding. We also examined the reliability of non-invasive techniques, such as XRF, XRD, FTIR, Raman spectroscopy and SEM-EDX, for studying the golden medallions.

\section{Results and discussion}

\section{In situ non-invasive analysis of the gold medallions by} portable XRF

For XRF, the depth of analysis depends on the nature of the elements assayed and on the energy of the fluorescing X-ray used to detect the elements (e.g., for $\mathrm{Pb}-\mathrm{L}$, $\mathrm{E}=9.2$ to $15.8 \mathrm{keV}$ or for $\mathrm{Pb}-\mathrm{M}, \mathrm{E}=2.3$ to $2.6 \mathrm{keV}$ ). In our study, it was possible to qualitatively and approximately quantitatively analyse the thin golden layer of the medallions. XRF analysis has been used to study the multi-layered samples. Multi-layer easel paintings were quantitatively analysed by X-ray fluorescence by De Viguerie et al. [14]. In the samples studied in this work (paintings with gold leaf on the surface), elements other than gold were also found that were part of the other layers of the cross-sections. A second drawback of this technique is that it does not give accurate quantitative information [3]. These two drawbacks suggest that the quantitative results obtained using this technique must only be considered to be approximations, for instance in 
Table 1 of this work.The quantification was performed using certified standards.

Five medallions (1-5) from the King Rooms and the other five (6-10) from the ceiling of Carlos V's lounge, located to the right and left side, respectively, of the Patio de las Doncellas (Court of the Maidens) were analysed. The elemental chemical composition of the external zones of the medallions analysed by portable XRF are shown in Table 1. The presence of $\mathrm{Cr}$ and $\mathrm{Pb}$, which we will discuss later in this work, were detected in the layer under the gold leaf and were not considered when quantifying the composition of the gold layer. The results showed that the artworks are composed of alloys of gold, silver, copper, and zinc, and different medallions had different concentrations of the metals. In all of the samples, gold had the highest concentration with percentages between 82 (approximately 20 karate) to $88 \%$ (approximately 21 karate). In each sample, the high proportion of gold was followed by silver, whose composition was between 11 and $5 \% . \mathrm{Cu}$ was present around $5 \%$ The percentages of zinc were the lowest of all the elements present, with about $1.5 \%$. The highest values of gold were found in the medallions from the ceiling of the Lounge of Carlos V (> 87\%).

Two ranges of gold and silver concentrations were found: a) $82 \%$ for gold and $11 \%$ for silver; b) $88 \%$ for gold and $5.5 \%$ for silver. The higher gold concentration corresponds to a lower silver concentration. These differences may be attributed to different restoration or/and a different gold content in the alloys used.

These alloys are used for coating. The purpose of substituting gold for other metals, such as silver and copper, is to produce the same effect but at a lower price. Zinc is added to facilitate the fluidness [3].

Gold is the material used most frequently for gilding in the Sevilla Reales Alcazares. Chaves [32] cited that the Royal Academy of San Fernando recommended that the restoration of Sevilla Reales Alcazares be conducted in 1896 with 20-karate (83.3\%) gold. The Academy assumed that, with time, the more recently used alloys would blend with the 20-karate gold. This percentage is similar to the gold concentration obtained in this study (Table 1).

The gilding created by traditional methods was fragile $[33,34]$. Therefore, the gilding should not be frequently cleaned. Additionally, excessive heat and light should be

Table 1 Quantitative analysis of the golden layer

\begin{tabular}{lllllllllll}
\hline Sample & $\mathbf{1}$ & $\mathbf{2}$ & $\mathbf{3}$ & $\mathbf{4}$ & $\mathbf{5}$ & $\mathbf{6}$ & $\mathbf{7}$ & $\mathbf{8}$ & $\mathbf{9}$ & $\mathbf{1 0}$ \\
Element & $\%$ & $\%$ & $\%$ & $\%$ & $\%$ & $\%$ & $\%$ & $\%$ & $\%$ & $\%$ \\
\hline $\mathrm{Cu}$ & 5 & 5 & 5 & 5 & 5 & 5 & 5 & 5 & 5 & 5 \\
$\mathrm{Zn}$ & 1.5 & 1.5 & 1.5 & 1.5 & 1.5 & 1.5 & 1.5 & 1.5 & 1.5 & 1.5 \\
$\mathrm{Ag}$ & 11 & 11 & 11 & 11 & 11 & 5.5 & 5.5 & 5.5 & 5.5 & 5.5 \\
$\mathrm{Au}$ & 82 & 82 & 82 & 82 & 82 & 82 & 88 & 88 & 88 & 88 \\
\hline
\end{tabular}

avoided, and extreme care should be taken when installing light and heat sources near the gilding surfaces to avoid creating localised areas of damage. All of these effects have contributed to the different alterations that were observed in the studied medallions.

\section{Analysis by non-invasive laboratory techniques, XRD, Raman and FTIR spectroscopies and SEM-EDX, performed on detached medallion fragments}

In this work, XRD, Raman and FTIR spectroscopy and SEM-EDX were used in the laboratory to directly analyse a fragment from the external part of the polychrome that had fallen down. After the study, the fragments were re-incorporated into the medallion. The sample was not altered during the study. By performing the study in the laboratory, more defined results are obtained because several parameters can be adjusted, such as the focalisation of the radiation, the intensity, the type of laser, the magnification of the microscopy and the filters, as opposed to in situ techniques such as a portable XRF system.

The XRD study of the golden layer was performed on a fragment separated from the medallion $(15 \times 8 \mathrm{~mm})$. Figure 1a shows the spot size of the $x$-ray beam used $(3 \times 1 \mathrm{~mm})$ and the focalisation on the golden zone (Figure 1d), the brown colour zone (Figure 1c) and on the back of the fragment (Figure 1b). The x-ray diffraction performed on the golden layer (Figure 2a) showed the presence of gold, gypsum (calcium sulphate dehydrated, $\mathrm{CaSO}_{4} \cdot 2 \mathrm{H}_{2} \mathrm{O}$ ), lead chromate (chrome yellow, $\left.\mathrm{PbCrO}_{4}\right)$, lead sulphate oxide $\left(\mathrm{PbSO}_{4} \cdot(\mathrm{PbO})_{2}\right)$ and quartz. On the golden layer, a black-coloured paint appeared. The XRD study revealed that this paint zone (Figure 2b) had a similar composition to the previous one. The intensity of the peaks, especially of the chrome yellow and lead sulphate oxide, decreased most likely because these compounds are present in deeper layers. The peaks intensity of quartz increased. The X-ray diffraction study performed on the white colour on the back of the sample (Figure 2c) showed the presence of gypsum.

Lead chromate was easily characterised by microRaman spectroscopy in a zone of the sample without the gold layer. The spectrum showed a band at $841 \mathrm{~cm}^{-1}$, which was attributed to the symmetric stretching of $\mathrm{CrO}_{4}^{2-}$, and at 407,381 , and $361 \mathrm{~cm}^{-1}$, corresponding to the bending modes of $\mathrm{CrO}_{4}^{2-}$ (Figure 3).

Lead chromate (chrome yellow, $\mathrm{PbCrO}_{4}$ ) is the most important of the commercial yellow pigments. Lead chromate is a crystalline material that can vary in shade from lemon yellow to orange depending upon the particle size, which in turn depends upon the precipitation conditions. Lighter shades usually contain lead sulphate, as was found in this study. Its use as a pigment dates from the beginning of the $19^{\text {th }}$ century. Chrome yellow 

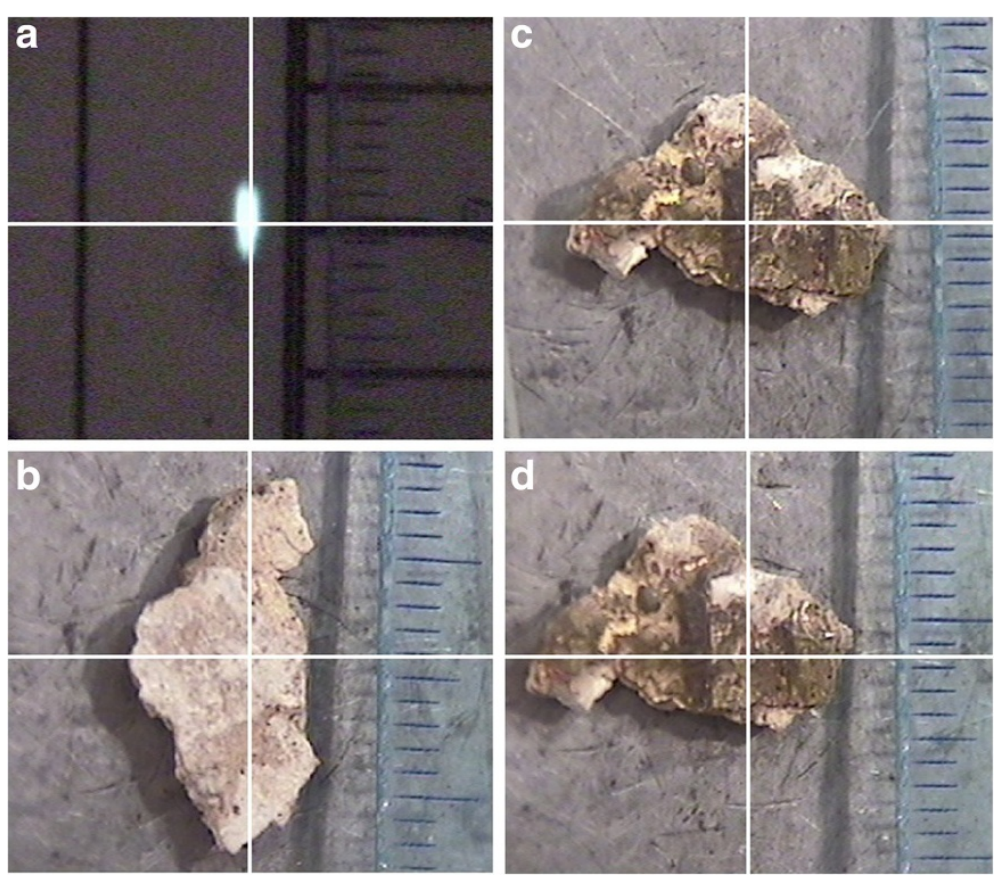

Figure 1 Photographs of the a) size of the x-ray spot used for x-ray diffraction, b) zone measured of the brown paint, c) zone measured on the back of the fragment and d) zone measured on the golden layer.

did not come into commercial production before 1818 . This pigment is no longer used in paints because more permanent yellow pigments are now available [35].

The FTIR spectra of the white-coloured layer (back of the sample, fig. not shown) showed bands at 3550, 3396, $1685,1621,1136,669$ and $601 \mathrm{~cm}^{-1}$, which confirmed the presence of gypsum. The Raman spectra also confirmed the presence of this mineral with a band at $1005 \mathrm{~cm}^{-1}$. This technique also detected carbon (bands at 1590 and $1315 \mathrm{~cm}^{-1}$ ) $[26,28]$. The SEM-EDX study was performed directly on the fragment without covering it with $\mathrm{C}$ because the gold, the major constituent of the sample (external surface), is a conductor metal. The EDX showed the presence of $\mathrm{Au}$ and small proportions of $\mathrm{Ag}$ and $\mathrm{Cu}$. $\mathrm{C}$ and $\mathrm{Si}$ were detected on the painting in the brown colour. These elements were characterised by this technique; however, the surface of the sample was partially charged during treatment with the electron beam in the SEM and even the conductive gold layer gold was present. Therefore, the obtained results were not accurate.

\section{Analysis of the golden support}

The XRD study performed on the fragment proved to be an adequate technique for characterising the phases present in the fragment. However, all the layers of the polychrome were not present in the detached fragments. The amorphous compounds, the phases present in low proportion or those with low reflection power were not detected by XRD.
While the XRF equipment has the advantage of being portable, and the XRD study was performed directly on a piece separated from the artwork (both techniques are non-invasive techniques), the SEM-EDX study permitted the study of the gold layer, but not of the back of the fragment due the non-conductivity of these compounds.

Small samples, where the gold was lost, were taken to gain complete knowledge of the medallion's components, and cross-sections were prepared and studied by SEM-EDX. This technique is micro-destructive, but it offers high magnification images with good resolution. The cross-section provided information about the composition of all of the support layers.

Two cross-sections, representatives of the medallions where the gold was lost, were selected for this study (Figure 4). Observation by optical microscopy showed different coloured layers. Five layers were observed in the cross-section of sample D1 (Figure 4a). At the top of the microphotography appears a layer of grey colour constituted by $\mathrm{Cl}, \mathrm{Na}, \mathrm{P}, \mathrm{Si}, \mathrm{Al}, \mathrm{Mg}, \mathrm{K}, \mathrm{Ti}, \mathrm{Fe}, \mathrm{Ca}, \mathrm{S}$ and $\mathrm{C}$ (Figure 5a); all of these elements are attributed to contamination of the paintings. The $\mathrm{P}$ may be present from the ivory black used in the surface in addition to the appearance of $\mathrm{Cr}$ and $\mathrm{Pb}$. This layer is followed by one of yellow colour constituted by $\mathrm{Pb}, \mathrm{Cr}, \mathrm{Ca}, \mathrm{O}$ and $\mathrm{Si}$ (Figure $5 \mathrm{~b}$ ) that confirms the presence of lead chromate previously characterised by XRD and Raman spectroscopy, a crack due to fracture was observed between the yellow and red layers. $\mathrm{Si}, \mathrm{Fe}$ and $\mathrm{Al}$ (Figure $5 \mathrm{c}$ ) appeared in the layer of red colour, 


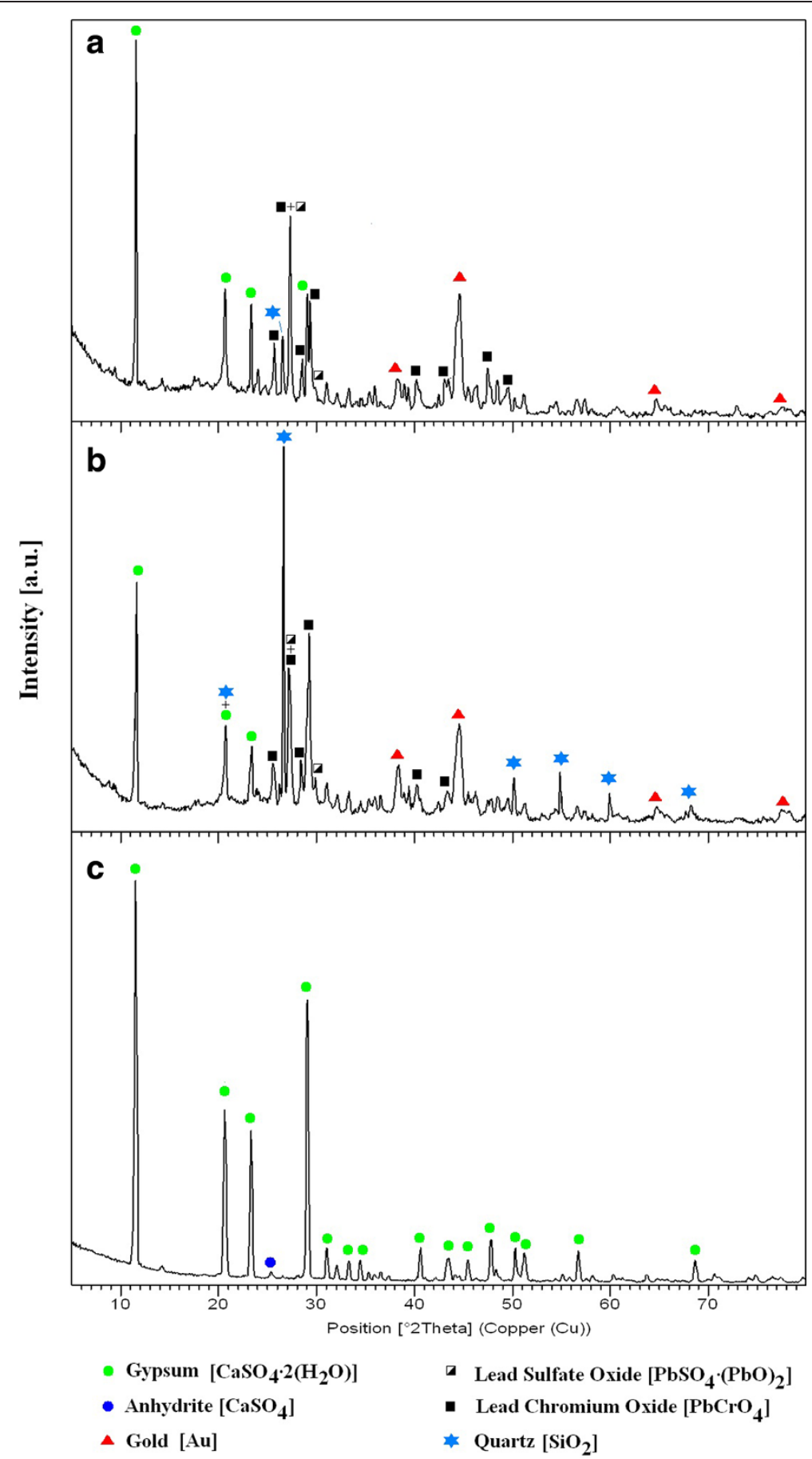

Figure 2 X-ray diagrams performed on the fragments of the a) golden layer, b) brown colour on the golden layer and c) back of the fragment.

which is typical of a bole layer frequently used for gilding. $\mathrm{Pb}$ was also detected with these elements. On top of this red layer appeared a layer with gold and silver, attributed to an old golden layer (Figure $5 \mathrm{~d}$ ). This layer is followed by a white-coloured layer constituted by $\mathrm{Pb}$ (Figure 5e), most likely from hydrocerussite and cerusite (lead white). These three layers were not detected by the other experimental techniques used in this work. These data confirmed the presence of other gilding performed over many years. Finally, a layer constituted by $\mathrm{S}$ and $\mathrm{Ca}$ (gypsum) appeared (Figure 5f).

Another cross-section (Figure 4b), prepared from a sample of medallion D8, showed two layers of yellow and white colour, constituted by lead chromate and 


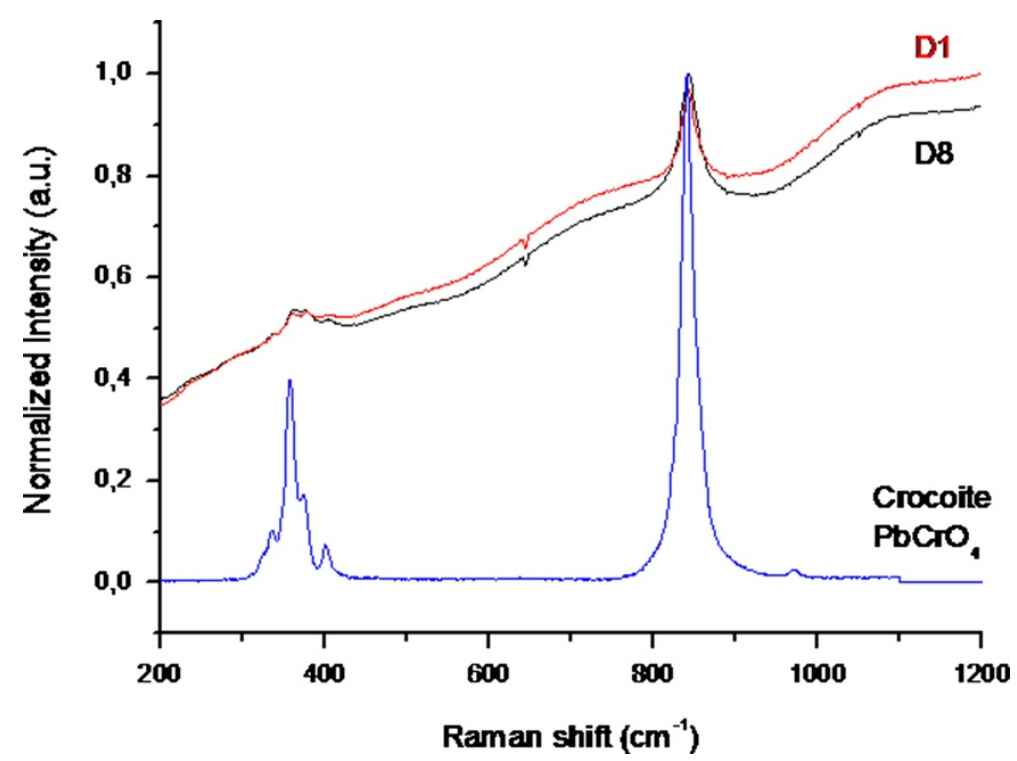

Figure 3 Raman spectra of two samples without the gold layer (D1 and D8) and the standard sample.

gypsum, respectively. In the gypsum layer, the punctual chemical analysis showed the presence of other minerals such as calcite $\left(\mathrm{CO}_{3} \mathrm{Ca}\right)$ (Figure 6a), apatite $\left(\mathrm{PO}_{4} \mathrm{Ca}_{3}\right)$ (Figure $\left.6 \mathrm{~b}\right)$, cinnabar (HgS) (Figure 6c) and silicoaluminates (Figure 6d). At the top of this cross-section was observed a thin layer with similar size and composition to the previously studied sample.

The modern SEM-EDX microanalysis provided information on elements with atomic masses larger than C. It should be noted that this technique cannot differentiate between samples with similar elemental composition or different crystal structure and stoichiometries. The EDX microanalysis of the cross-sections provided information about the chemical elements present in the various layers and was used to suggest the identification of compounds. These latter experiments were a valuable preliminary orientation.

The FTIR study showed the presence of bands from an organic compound at 2955, $2920\left(-\mathrm{CH}_{2},-\mathrm{CH}_{3}\right)$ and $1742 \mathrm{~cm}^{-1}(\mathrm{C}=\mathrm{O})$. We suggest the presence of linseed oil in the preparation layer on which the gold layer is placed for two reasons: first, a comparison between the spectra from the cross-section samples and the linseed oil standard yields a good fit, and second, this gilding technique has been described in ancient recipes.

Mass spectrometry (Figure 7) (desorption and pyrolysis curves) of a sample taken from the lead chromate layer where the golden layer was lost showed the presence of linseed oil. The following compounds were also detected: nonanal, nonanone 6-octadecenoic nonanoic, hexanoic acid (caused by the breakdown and the oxidation of linseed and/or oxidation of the chains that compose the oil of linseed: oleic, linoleic and linolénic) a by-product of azelaic acid (a dicarboxylic acid also derived from breaking and subsequent oxidation). Azelaic acid is very difficult to remove because it remains in ancient artwork due to its solubility in water, which would indicate that the medallion has been kept well preserved in a special atmosphere. Linseed oil and animal glue were also characterised in the desorption curves of the other samples studied in this work.

\section{Lead chromate in the gilding}

In this study, a yellow layer of lead chromate mixed with linseed oil was found under the gold leaf. For the application of gold surfaces, pieces of gold leaf are attached to the desired areas using an adhesive, mordant such as linseed oil, lead white, verdigris, varnish and bole [6-8]. The gilding is traditionally made with a thin piece of gold metal leaf applied to a gypsum layer and covered with a red or ochre layer of bole. In previous works, we observed in sculptures, altarpieces, etc. that the gold leaf was usually applied onto a bole. The bole is a mixture of clay minerals, iron oxides and organic compounds, such as oils. In addition, the bole is unctuous and capable of being polished. It has served, since early mediaeval times, as a ground for gilding [35]. For carved decorative pieces, a linseed oil added with a pigment, such as lead white, or coloured pigments was used as the support. In the study of four $17^{\text {th }}$ century Albanian icons [36], gold powder was used in the mixture with pigments containing $\mathrm{Ca}, \mathrm{Fe}$ and $\mathrm{Pb}$ for creating yellow tonalities. On Greek icons from the $16^{\text {th }}$ century [37], the gold leaf was attached to the support using animal glue mixed with yellow bole. Pararealgar was found between two layers of gilding in other Greek icons [38]. Yellow bole was also detected in Cretan icons from the 17th century [39]. Yellow support made from $\mathrm{Pb}-\mathrm{Sn}$ was found in mural 

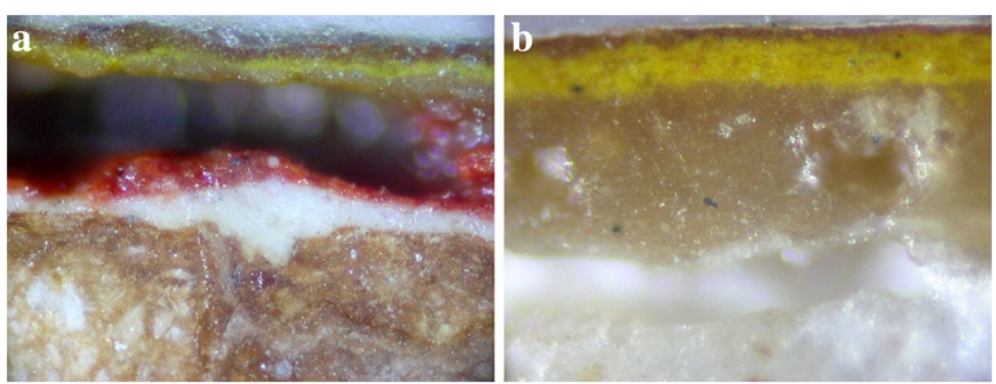

Figure 4 Microphotographs of cross-sections corresponding to two samples (D1 and D8) extracted from the medallions.

paintings from Northern Italy [40]. We have also detected complex mixtures in the gilding of ceramic and stone sculptures composed of compounds such as minium, hydrocerusite, cerusite and linseed oil [8].

In many studies, false gold was found in the form of copper-zinc powders or silver covered with resin [4]. Rampazzi et al. [41] found a yellow layer composed of a mixture of chrome yellow, iron oxides and an organic compound (most likely an oil) used as a mordant under the gold leaf. In our study, we also found the presence of lead chromate under the gold leaf. It is difficult to determine whether the lead chromate was used as a support for the gold leaf or as false gold. In the medallions studied in this work, it is clear that the gilding was completed after 1818 in an intervention using linseed oil to attach the gold layer. The lead chromate was used after 1818 and was likely applied during the restoration of Reales Alcazares of Sevilla performed in the $19^{\text {th }}$ century. The study by SEM-EDX confirmed the presence of another gilding in the medallions, most likely performed during ancient times when a gold mixture with silver deposited on a bole layer was used.

\section{Experimental}

Materials

Several of the golden medallions studied in this work, which represent the coat of arms of the Leon and Castile Kingdoms, are shown in Figure 8. Some medallions show a high degree of alteration, and some of them have lost their gilding layer (Figure 8). The elemental chemical analysis was performed on ten medallions.

Small fragments/flakes from the external part of the polychrome fell down and were used for the laboratory studies. After the studies, the fragments were re-incorporated into the medallion.

Additionally, small samples were taken from several parts of the medallion where the gilding had been completely

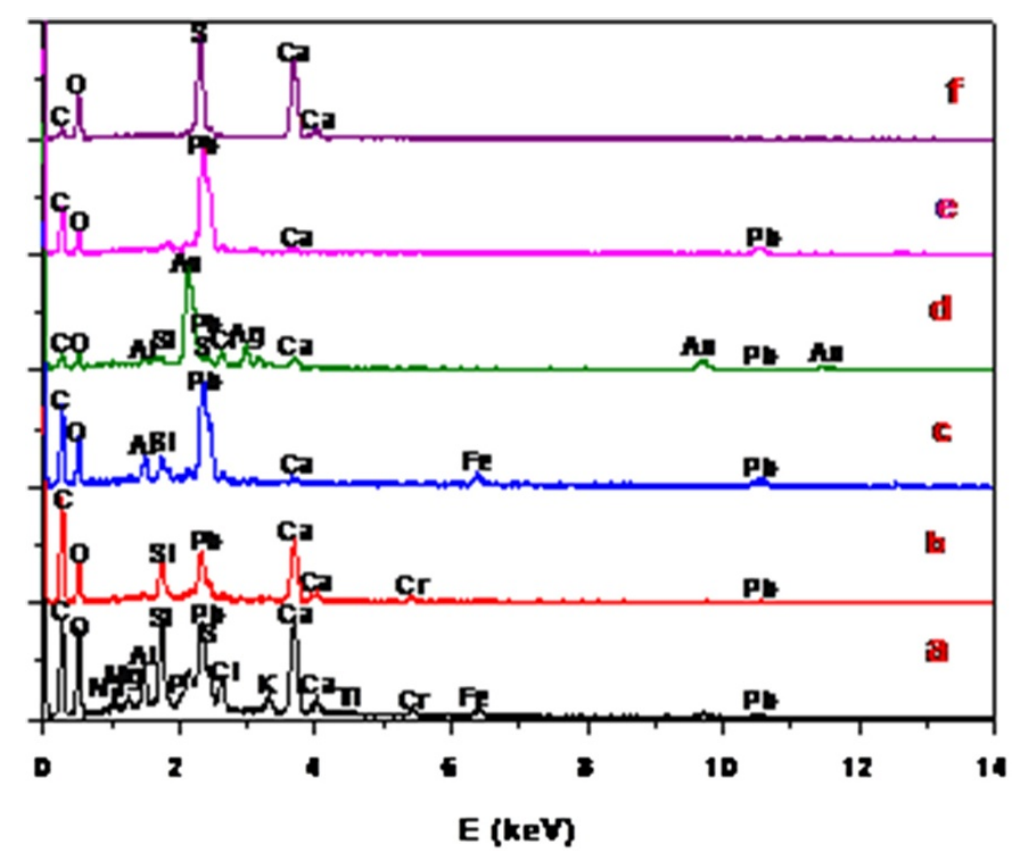

Figure 5 EDX elemental analysis performed on the different layers of the cross-section. 


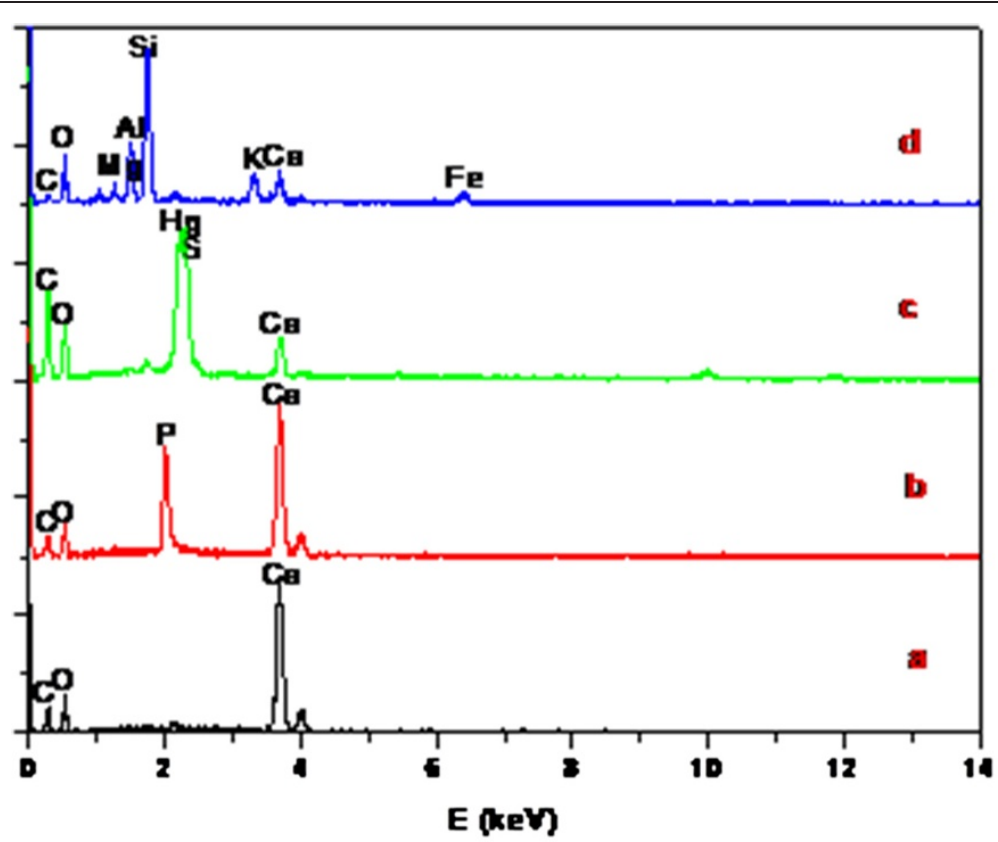

Figure 6 EDX elemental analysis performed on different points of the cross-section of the support layer.

lost. Cross-sections were prepared from these samples to study the gilding technique.

\section{Methods}

\section{Cross-sections preparation}

The cross-sections were prepared following the methodology described by Duran and Duran et al. [29,42] and
Khandekar [43]. They were observed and photographed with a Nikon OPTIPHOT optical microscope $(25 \times, 50 \times$ and $100 \times$ magnification).

\section{X-Ray fluorescence analysis}

The elemental composition was determined using a Bruker Tracer III-SD portable X-Ray fluorescence spectrometer
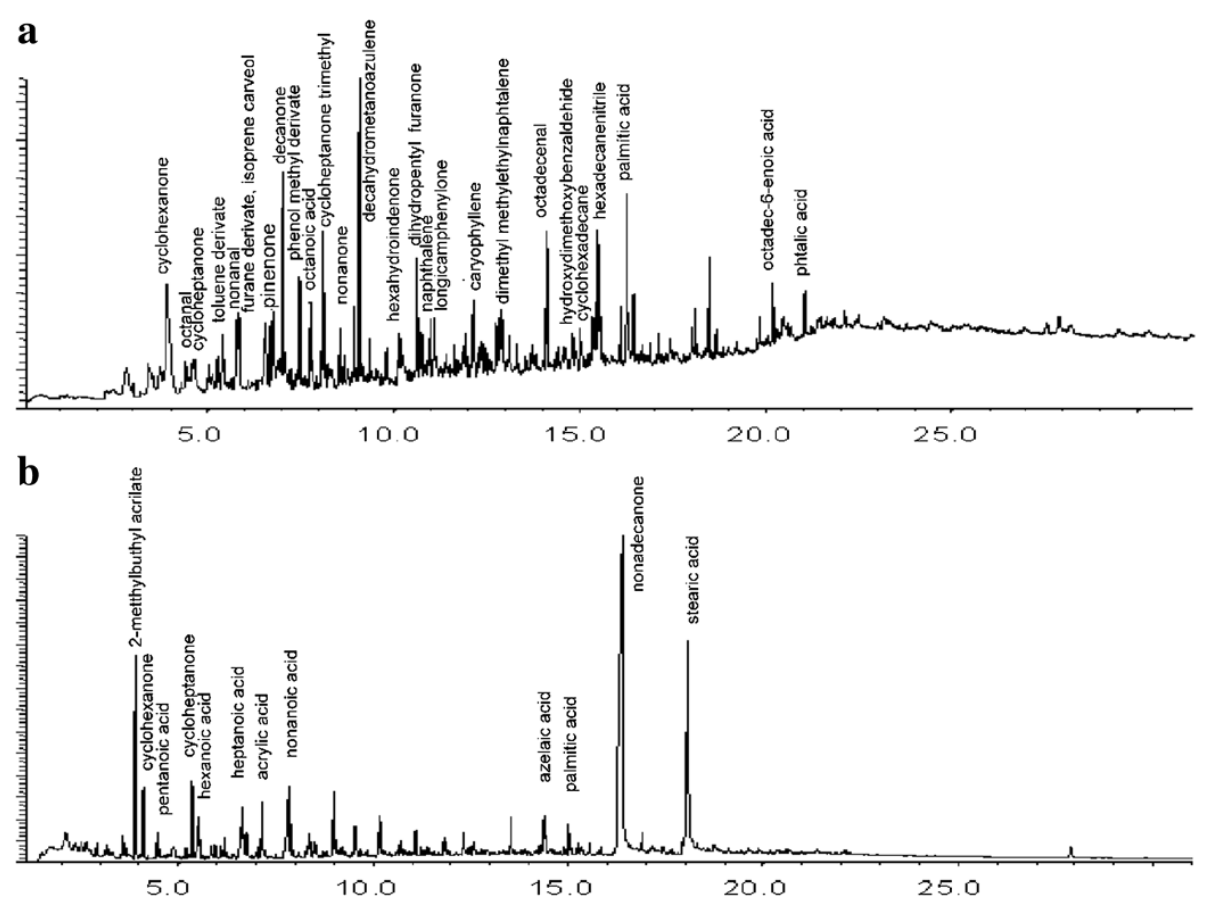

Figure 7 Mass spectrometry curves (desorption and pyrolysis) of the protection layer on the lead chromate. 
equipped with a $10 \mathrm{~mm}^{2} \mathrm{X}$-flash solid state silicon drift detector (SDD) with a typical resolution of $147 \mathrm{eV}$. The Rh $\mathrm{x}-$ ray tube was operated at $55 \mathrm{kV}, 15 \mathrm{~mA}$ and $4 \mathrm{~W}$ during $100 \mathrm{~s}$ of lifetime. The energy dispersive system's typical peak overlap and matrix effects did not allow for a straightforward elemental quantification because the intensity of an element's peak was not directly proportional to the element's concentration. Instead, the intensity was also a function of the concentration of other elements present in the sample [44]. Therefore, quantification was always dependent on standard samples with an equivalent elemental matrix measured under the same conditions. We quantified the samples using the fundamental parameters method [45] and the software associated with the equipment (Bruker Spectra EDX). The fundamental parameter evaluation procedure was calibrated and set up to analyse 14 certified pure metals, from silicon (lightest element) to lead (heaviest element), that were used as reference materials to compose the internal software library of elemental sensitivities. The results of the analysis were expressed in weight percentage (wt\%). The results must only be considered to be approximated.

\section{X-Ray powder diffraction}

Conventional X-ray powder diffraction was performed on a PANalytical X'PERT Pro MPD diffractometer equipped with a parabolic mirror incident beam (W / Si) and a $2 \mathrm{~mm}$ mask to define the area of analysis with lambda =
1.540509A at $45 \mathrm{kV}$ and $40 \mathrm{~mA}$. A solid-state PIXcel detector was used. The study was performed directly on a fragment by XRD.

\section{Micro-FTIR and micro Raman spectroscopy}

$\mu$-FTIR spectra were recorded using a Nicolet 510 apparatus (Source: Globar, Detector: MCT) in reflection mode with a Nic-Plan optical microscope confocally coupled to the spectrometer. The experiments were performed directly on the fragment. The spot size was approximately $5 \mu^{2}$, and at least 200 scans were accumulated for each spectrum at a $4 \mathrm{~cm}^{-1}$ resolution.

The dispersive integrated Horiba Jobin-Yvon LabRam HR800 system was used to record the Raman spectra of the golden support. The experiments were performed directly on the fragments separated from the medallion, similarly to the $\mu$-FTIR experiments. Two external visible diode lasers (solid-state source) are available in this apparatus at $532 \mathrm{~nm}$ (green) and at $784.5 \mathrm{~nm}$ (red). However, we mainly used the $784.5 \mathrm{~nm}$ laser to minimise the fluorescence of the organic medium or of the pigments themselves. The equipment has a charge-coupled device (CCD) detector and a grating of 680 groves/nm. An optical microscope was confocally coupled to the Raman spectrometer. The size of the analysed zones depended on the microscopy magnification. In this work, the size was approximately $5 \mathrm{\mu m}^{2}$. Each Raman spectrum was recorded for 8-12 minutes

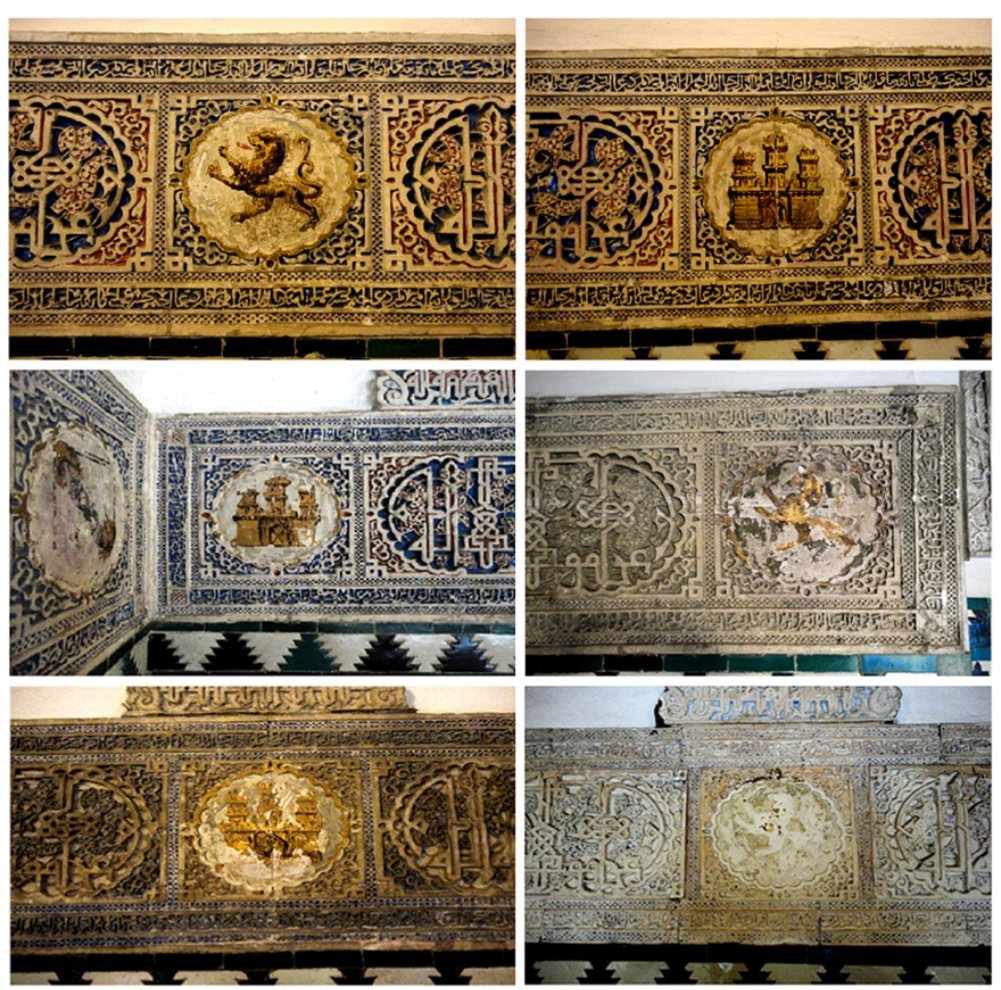

Figure 8 Photographs of the medallions studied in this work showing the different degrees of alteration. 
and with a spectrum resolution of $2 \mathrm{~cm}^{-1}$. Power values measured during the experimental process were approximately $16-40 \mathrm{~mW}$, to avoid damaging components of the crosssections.

\section{Energy Dispersive X-Ray analysis}

Elemental chemical analyses of the cross-sections were obtained using a HITACHI S-4800 SEM instrument equipped with a Link ISIS energy dispersive X-ray (EDX) analyser at an accelerating voltage of $20 \mathrm{kV}$.

\section{Mass spectrometry}

Mass spectrometry was performed on the same sample used for cross-section preparation $[46,47]$. The pyrolysis was performed in two steps: a) desorption at $350^{\circ} \mathrm{C}$ and b) pyrolysis at $500^{\circ} \mathrm{C}$. The pyrolysis method used was DoubleShot. An micro-furnace (model 2020, Frontier Laboratories Ltd) connected to a GC/MS Agilent 6890 system with a silica capillary column (HP 5 MS, $30 \mathrm{~m} \times 0.25 \mathrm{~m} \times 0.25 \mu \mathrm{m}$ I.D.) and a mass selective detector (Agilent 5973) was used. The databases used to interpret the chromatograms were Wiley5 and the NIST2007 Mass Spectral Library.

\section{Conclusions}

This work describes the use of non-invasive techniques to study golden medallions from Sevilla Reales Alcazares. XRF was performed in situ and XRD, SEMEDX, FTIR and $\mu$-Raman spectroscopy were performed on a fragment that had fallen down from a medallion, which was re-incorporated into its original position after the study. The gold layer supports were also studied from cross-sections prepared from samples collected from the medallions.

XRF analysis performed in situ with portable instrument showed that the leaf adhered to the surface is composed of gold, copper, silver and zinc. The percentages of the different metals indicate the presence of two groups of alloys most likely used during two different steps of construction and/or restorations or due to small differences in the gold alloys. The XRF portable equipment provided important information about the external layers of the polychrome (not only about the gilding layer). However, chemical distribution of different layers showed difficulties. Obtaining information about the composition of all the layers of the gilding was necessary to perform the study by XRD. The XRD experiments performed on a fragment showed that a layer of lead chromate followed by a layer of gypsum were present under the gold. The lead chromate also contained a small portion of lead sulphate oxide. This pigment (lead chromate, yellow chrome) was used either as the mordant, in addition to linseed oil, under the gold layer or as false gold. The presence of this pigment in the gilding was only previously reported once in the literature. The portable XRF and XRD did not give information about the black paintings located on the golden layer. The $\mu$-Raman and SEM-EDX analyses confirmed the presence of black carbon and ivory black because $\mathrm{P}$ was also detected. The presence of linseed oil was confirmed by mass spectrometry and FTIR.

The presence of lead chromate suggests that the actual golden layer was added after 1818. A gold layer appeared under the yellow colour (lead chromate) in one of the cross-sections studied by SEM-EDX thus confirming the previous gilding.

The non-invasive techniques provided useful information about the characterisation of the components of the golden medallion, and the results provided by the different techniques correspond well with one another. However, complete characterisation of the medallions required the use of other techniques such as mass spectrometry and SEM-EDX.

\section{Abbreviations}

XRF: X-ray fluorescence; XRD: X-ray diffraction; FTIR: Fourier transformed infrared; SEM: Scanning electron microscopy; EDX: Energy dispersive X-ray.

Competing interests

The authors declare that they have no competing interests.

\section{Authors' contributions}

MD coordinated the study. JL conceived the study and performed the part of the experiments and drafted the manuscript. MC performed the scanning electron microscopy. JM performed the X-Ray diffraction. I performed the taken and preparation of the samples. C performed the X-ray fluorescence. A worked on data analysis and interpretation. All the authors read and approved the final manuscript.

\section{Acknowledgements}

The authors are indebted to the Patronato de los Reales Alcazares de Sevilla for their collaboration with our investigation. The financial support of the Spanish Commission interministerial de Ciencia y Tecnología (CICYT) under project BIA2009-12618 and the Junta de Andalucia (TEP-6558) are also acknowledged.

\section{Author details}

${ }^{1}$ Materials Science Institute of Seville (CSIC-Sevilla University), Avda Americo Vespucio 49, 41092 Seville, Spain. ${ }^{2}$ Technical Architecture Faculty University of Seville, Avda Reina Mercedes s/n, 41012 Seville, Spain. ${ }^{3}$ Department of Prehistory and Archaeology, University of Seville, Maria de Padilla s/n, 41004 Seville, Spain. ${ }^{4}$ Department of Chemistry and Soil Sciences, School of

Sciences, University of Navarra, Irunlarrea 1, 31080, Pamplona, Spain.

Received: 31 December 2012 Accepted: 18 February 2013

Published: 3 April 2013

References

1. Lobato Dominguez J, Martin Esteban A: Reales Alcázares de Sevilla. Barcelona: Editorial Escudo de Oro; 1998

2. Almagro A: Los Reales Alcázares de Sevilla. Artigrama 2007, 22:155-185.

3. Sandu ICA, de Sá MH, Pereira MC: Ancient gilded art objects from European cultural heritage: a review on different scales of characterization. Surf Interface Anal 2011, 43:1134-1151.

4. Duran A, Perez-Rodriguez $J \mathrm{~L}$, de Haro MC J, Herrera LK, Justo A: Degradation of gold and false gold used as gilding in the cultura heritage of Andalusian, Spain. J Cult Herit 2008, 9:184-188.

5. Thompson DVT: The Materials of Medieval Paintings. London: George Allen and Unwin Ltd; 1936. 
6. Katsibiri O, Boon J: Investigation of the gilding technique in two postByzantine wall paintings using micro-analytical techniques. Spectrochim Acta 2004, 59:1593-1599.

7. Katsibiri O: Investigation of the Technique and Materials Used for Mordant Gilding on Bizantine and post-Byzantine Icons and Wall Paintings. PhD Thesis. University of Northumbria Newcastle; 2002.

8. Duran A, Perez-Rodriguez $\lrcorner \mathrm{L}$, Jimenez de Haro MC: Study of the gilding technique used in polychromed stones and ceramics by dedicated laboratory-made micro x-ray diffraction and complementary techniques. Anal Bioanal Chem 2009, 394:1671-1677.

9. Vancy D: Thompson (transl): The Craftsma's Handbook (Il libro dell'arte by Cennini C). New York: Dover; 1960

10. Papadopoulou DN, Zachariadis GA, Anthemidis AN, Tsirliganis NC, Stratis JA: Development and optimization of a portable micro-XRF method for in situ multi-element analysis of ancient ceramics. Talanta 2006, 68:1692-1699.

11. Hocquet FP, Gamir HP, Marchal A, Clar M, Oger C, Strivay D: A remotecontrolled XRF system for field analysis of cultural heritage objects. X-Ray Spectrom 2006, 37:304-308.

12. Trojanowicz M: Analytical microtechniques in archeometry. Microchimica Acta 2008, 162:287-288.

13. Han $X Y$, Zhuo SJ, Shen RX, Wang PL, Ji A: Comparison of the quantitative results corrected by fundamental parameter method and difference calibration specimens in X-ray fluorescence spectrometry. J Quant Spectrosc Radiat Transfer 2006, 97:68-74.

14. De Viguerie $L$, Walter $P$, Laval E, Solé VA: Revealing the sfumato technique of Leonardo da Vinci by X Ray fluorescence spectroscopy. Angew Chem 2010, 122:1-5.

15. Maja D, Gajic-Kvascev, Maric-Stojanoic M, Jantic-Helnemann R, Kvascev G, Andric $V$ : Non-destructive characterization and clasification of ceramics artefacts using pEDXRF and statical pattern recognition. Chem Cent J 2012, 6:102-121.

16. Herrera LK, Duran A, de Haro MC J, Perez-Rodriguez JL, Justo A: Study of barroque artworks by non-destructive techniques. Coalition Newsletter 2007, 14:10-14.

17. Herrera LK, Duran A, Franquelo ML, Gonzalez-Elipe A, Espinos JP, RubioZuazo J, Castro GR, Justo A, Perez-Rodriguez JL: Study by grazing incident diffraction and surface spectroscopy of amalgams from ancient mirrors. Cent Eur J Chem 2009, 7:47-53.

18. Rubio-Suazo J, Castro GR: Pobing buried interfaces by simultaneous combination of X-ray diffraction (SXRD) and hard X-ray photoelectron spectroscopy /HAXPES, up to 15KeV). Rev Adv Mater Sci 2007, 15:79-86.

19. Duran A, Herrera LK, de Haro MC J, Justo A, Perez-Rodriguez JL: Nondestructive analysis of cultural heritage artefacts from Andalusia, Spain by X-ray diffraction with Göbel mirrors. Talanta 2008, 76:183-188.

20. Castro K, Sarmiento A, Princi E, Perez-Alonso M, Rodriguez-Laso MD, Vicini S, Madariaga JM, Pedemonte E: Vibrational spectroscopy at the service of industrial archaeology: Nineteenth-century wallpaper. Trends Anal Chem 2007, 26:347-359.

21. Bersani D, Lottici PP, Vignali F, Zanichelliu G: A study of medeval iluminated manuscripts by means of portable Raman equipments. J Raman Spectrosc 2006, 37:1012-1018.

22. Andrikopoulus KS, Danilia S, Roussel B, Jansens K: In vitro validation of a mobile Raman-XRF micro-analytical instrument's capabilities on the diagnosis of Byzantine icons. J Raman Spectrosc. 2006, 37:1026-1034.

23. Adar F, LeBourdon G, Reffner J, Whitly A: FT-IR and Raman spectroscopybon a united plataform: A technology hose time has come. Spectroscopy Magazine 2003, 18:34-40.

24. Giakoumaki A, Osticioli I, Anglos D: Spectroscopy analysis using a hybrid LIBS-Raman system. App Phys A 2006, 83:537-541.

25. Belfot-Gurlet L, Pages-Camagna S, Coupry C: Raman spectroscopy in art and archaeology. J Raman Spectosc 2006, 37:962-965.

26. Franquelo ML, Duran A, Herrera LK, de Haro MC J, Perez-Rodriguez JL: Comparison between micro-Raman and micro-FTIR spectroscopy techniques for the characterization of pigmentsd from Southern Spain Cultural Heritage. J Mol Struct 2009, 924-926:409-412.

27. Duran, Perez-Rodriguez JL, Espejo T, Franquelo ML, Castaing J, Walter P: Characterization of illuminated manuscripts by laboratory-made portable XRD and micro-XRD systems. Anal Bioanal Chem 2009, 395:1997-2004.
28. Duran, Franquelo ML, Centeno MA, Espejo T, Perez-Rodriguez JL: Forgery detection on an Arabic illuminated manuscript by micro-Raman and X-ray fluorescence spectroscopy. J Raman Spectrosc 2011, 42:48-55.

29. Duran A, de Haro MC J, Perez-Rodriguez JL, Franquelo ML, Herrera LK, Justo $\mathrm{A}$ : Determination of pigments and binders in Pompeian wall paintings using synchrotron radiation high resolution X-ray poder diffraction and conventional spectroscopy chormatography. Archaeometry 2010, 52:286-307.

30. Salvi A, Langerame F, Macchia A, Sammartino M, Tabaso M: XRS characterization of (copper-based) coloured stains formed on limestone surfaces of outdoor Roman monuments. Chem. Cent. J. 2012, 6(suppl 2):510.

31. Genga A, Baglivi F, Siciliano M, Siciliano T, Tepor M, Miccoci G, Alello D: SEM-EDS investigation on PM10 data collected in Central Italy: Principal component analysis and hierarchical cluster analysis. Chem. Cent. J. 2012, 6(suppl 2):53.

32. Chaves González MR: El Alcázar de Sevilla en el Siglo XIX. Sevilla: Patronato del Real Alcazar de Sevilla; 2004.

33. Jenkins M: Gilding Techniques, Care and Maintenance, Information for Historic Building Owners. Edimburgo: Historic Scotland; 2007.

34. Bigelow D, Cornu E, Landrey G: Van Home C (eds) in: Gilded wood: Conservation and History. Madison: Sound View Press; 1991.

35. Gettens RJ, Stout GL: Painting Materials. New York: Dover Publications Inc; 1966.

36. Civici N, Demko O, Clark RJH: Identification of pigments use don late $17^{\text {th }}$ century Albanian icons by total reflection X-ray fluorescence and Raman microscopy. J Cult Herit 2005, 6:157-164

37. Danilia S, Bikiaris DS, Burgio L, Gavaala P, Clark RJH, Chryssoulakis Y: An extensive non-destructive and micro-spectroscopy study of two postByzantine overpainted icons of the $16^{\text {th }}$ century. J Raman Spectrosc 2002, 33:807-814

38. Burgio L, Clark RJH, Theodoraky K: Raman spectroscopy of Greek icons: identification of unusual pigments. Spectrochim Acta Part A 2003, 59:2371-2389

39. Karapanagiotis I, Wei S, Daniilia S, Minopoulou E, Mantouzirs D, Rosenberg E: Stassinopoulous: Analytical Investigation of painting techniques used in icons of the Cretan school of iconography. In ART2008 $9^{\text {th }}$ International Conference Non-destructive Testing and Microanalysis for the Diagnostic and Conservation of the Cultural and Environmental Heritage, May $25^{\text {th }}-30^{\text {th }}$, Jerusalem. 2008

40. Sandu ICA, Bracci S, Sandu I, Lobefaro M: Integrated analytical study for the authentication of five Russian icons (XVI-XVII centuries). Microsc Res Tech 2009, 72:755-762.

41. Rampazzi L, Rizzo B, Colombo C, Conti C, Realini M, Barolucci U, Colombini MP, Spiriti A, Facchin L: The stucco decorations from St. Lorenzo in Laino (Como, Italy): The materials and the techniques employed by the "Magistri Comacini". Anal Chim Acta 2008, 630:91-100.

42. Duran-Benito A, Herrera-Quintero LK, Robador-Gonzalez MD, PerezRodriguez JL: Color study of Mudejar paintings of the pond found in the palace of "Reales Alcazares" in Seville. Color Res and Appl 2007, 32:489-495.

43. Khandekar N: Preparation of cross-section from easel paintings. Rev Conserv 2003, 4:52-64

44. Van Grieken RE: Markowicz AA () Handbook of X-ray spectrometry methods and techniques. New York: Marcel Dekker; 1993.

45. Criss JW, Birks LS: Calculation methods for fluorescent X-ray spectrometry empirical coefficients vs. fundamental parameters. Anal Chem 1968, 40:1080-1086

46. Lluveras-Tenorio A, Andreotti A, Bonaduce I, Bouland, Cotte M, Roque J, Colombibi M, Vendrell-Saz M: Mass spectrometric and synchrotron radiation based technique for the identification and distribution of painting materials in samples from paints of Josen Maria Saint. Chem. Cent. J. 2012, 6:45

47. Casoli A, Santoro S: Organic materials in the wall paintings in Pompei: a case study of Insula del Centenario. Chem. Cent. J. 2012, 6:107.

doi:10.1186/2050-7445-1-4

Cite this article as: Perez-Rodriguez et al:: Non-invasive analytical techniques applied to characterize the components of ancient golden medallions. Heritage Science 2013 4:4 